\title{
Implicaciones éticas del capitalismo y de la economía de mercado en la familia: relectura y tareas de la teología moral desde el Documento de Medellín"
}

\author{
Diego Agudelo Grajales*
}

Recepción: 15 de agosto de 2018 • Aprobación: 12 de septiembre de 2018

\section{Resumen}

Este artículo, inspirado en el capítulo 3 "Familia y demografía" del Documento de Medellín (1968), advierte en la introducción que es la familia la que más sufre las consecuencias de los "círculos viciosos" y de las transformaciones que se generan en el orden económico. Por tanto, la propuesta consiste en tratar desde diferentes niveles de análisis el impacto del capitalismo y de la economía de mercado en esta institución tan esencial como es la familia. Medellín es el inspirador, pero se revisará críticamente la posición de la Iglesia a través de las encíclicas sociales reconociendo su valor profético de denuncia pero también su silencio, lo que ha significado una legitimidad de este sistema capitalista.

Palabras clave: capitalismo, Doctrina Social de la Iglesia, economía, ethos, familia, teología moral.

* Artículo producto del proyecto de investigación con código 4462, aprobado y financiado por la Pontificia Universidad Javeriana de Cali (2017-2018). Fue presentado en el Primer Congreso Internacional de Teología Latinoamericana y del Caribe: 50 años de Medellín: Iglesia y signos de los tiempos, desarrollado en la Universidad Santo Tomás entre el 16 y el 19 de octubre de 2018. Citar como: Agudelo Grajales, D. A. (2018). Implicaciones éticas del capitalismo y la economía de mercado en la familia: relectura y tareas de la teología moral desde el Documento de Medellín. Albertus Magnus, IX(2), 35-57. Doi: https://doi.org/10.153322/5005413.5099

* Pontificia Universidad Javeriana. Cali, Colombia. Orcid: https://orcid.org/0000-00019089-595X. Correo electrónico: dagudelo@javerianacali.edu.co 


\title{
Ethical implications of capitalism and the market economy in the family: rereading and tasks of moral theology from the Document of Medellín
}

\begin{abstract}
This article, inspired by chapter III Family and Demography of the Document of Medellin (1968), warns in the introduction that it is the family who suffers most from the consequences of the "vicious circles" and the transformations that are generated in the economic order. Therefore, the approach is to treat from different levels of analysis the impact of capitalism and the market economy in this essential institution as is the family. Medellín is the inspirer, but the position of the Church will be critically reviewed through the social encyclicals recognizing its prophetic value of denunciation but also its silence, which has meant a legitimacy of this capitalist system.
\end{abstract}

Keywords: capitalism, social doctrine of the church, economy, family, ethos, moral theology.

\section{Impli fas da teologia moral do Documento de Medellín}

\section{Resumo}

Este artigo, inspirado no capítulo III, Família e Demografia do Documento de Medellín (1968), alerta na introdução de que é a família que mais sofre com as conseqüências dos "círculos viciosos" e as transformações geradas na ordem econômica, portanto, a proposta é tentar, a partir de diferentes níveis de análise, o impacto do capitalismo e da economia de mercado nessa instituição tão essencial como a família. Medellín é o inspirador, mas a posição da Igreja será revista criticamente pelas encíclicas sociais, reconhecendo seu valor profético de denúncia, mas também seu silêncio, o que significou uma legitimidade desse sistema capitalista.

Palavras-chave: capitalismo, doutrina social da igreja, economía, ethos, familia, teologia moral. 


\section{Introducción}

Decía monseñor Oscar Romero que "la sociedad actual es como una sociedad anónima en que nadie se quiere echar la culpa, y todos somos responsables" (Romero, Cardenal, Martín-Baró y Sobrino, 1980, p. 273). Una de esas culpas que nadie quiere darse es la de los pobres, la de aquellos que con sus rostros reclaman justicia, solidaridad; es la pobreza real, no aquella que se manipula semánticamente. Este artículo, inspirado en el capítulo 3 "Familia y demografía” del Documento de Medellín (Consejo Episcopal Latinoamericano [Celam], 1968), advierte en la introducción que es la familia la que más sufre las consecuencias de los "círculos viciosos" y de las transformaciones que se generan en el orden económico. En consecuencia, la propuesta busca tratar desde diferentes niveles de análisis uno de los meollos más importantes en la actualidad, tal y como es el impacto del capitalismo y de la economía de mercado en esta institución como es la familia.

Conscientes de que no será una lectura cómoda e incluso que pueda ser desautorizada desde lo epistémico de las ciencias económicas, lo que pretende es analizar cómo las familias actuales están haciendo resonancia a ese consumismo consecuente de este tipo de economía y va perdiendo su significación como dadora de sentido y entrando en esa lógica del consumo y, por ende, dejando de lado, por ejemplo, la experiencia sacramental de la alianza del matrimonio por la figura del contrato mercantil. El interés tampoco es hacer un análisis de coyuntura de la realidad de la crisis económica, aunque supone hacer una referencia a ella.

El lugar epistemológico para hacer este análisis es a partir del reconocimiento de una ética económica en cuanto se sabe que la ética está inserta en la vida de las personas y los pueblos, por lo cual ha de estar integrada con ciertos valores para justificar el logro de resultados y el modo de alcanzarlos. El problema ético que nos preocupa está en torno a los fines y medios en la actividad económica, en tanto supone un ejercicio intencionado que supera los mecanismos económicos y libres o la ganancia indiscriminada. La empresa y la economía pertenecen al reino de los medios, no de los fines (Hinkelamert, 1970). Por esta misma razón, es concebible que este problema esté en relación con las teorías del desarrollo y de los sistemas económicos que lo sustentan, pues las fronteras se abren y se interrelacionan de modo que surgen sistemas más integrados.

Tampoco se desconoce la pretensión de plantear la economía como una ideología, específicamente neoliberal, con pretensiones de no ser simplemente un programa económico, sino de ser un programa que transforma a la sociedad 
en todas las dimensiones de la realidad y que en cierto modo fundamenta o está fundamentado en una epistemología cartesiana que fragmenta y compartimenta la realidad hasta el punto de ver lo que sucede sin conexión interna. Así, todo en la sociedad está a merced de los criterios de valoración del neoliberalismo económico, pues, a pesar de reconocer el estado actual de la crisis de la economía mundial manifestada en la destrucción de la naturaleza y el crecimiento de los pobres en el mundo y del establecimiento de la marginación como legítima, su forma de contrarrestarla es insistiendo en la intervención de la "mano invisible" que reorganiza el estado actual de las cosas mediante la autorregulación en función de la armonía y el equilibrio como societas perfecta. Supone también de los individuos, pueblos y gobiernos la aceptación de este principio y su modo de revelarse a través del mercado para garantizar su éxito. Estas son semejanzas interesantes con la comprensión tradicional del papel de la Iglesia, que pueden dar lugar a otro tipo de análisis y llamados:

Nuestro deber pastoral nos lleva a hacer un apremiante llamado a los gobiernos y a todos los que tienen alguna responsabilidad al respecto, para que den a la familia el lugar que le corresponde en la construcción de una ciudad temporal digna del hombre, y le ayuden a superar los graves males que le afligen y que pueden impedir su plena realización. (Celam, 1968, n. 3)

Un detalle importante a tener en consideración es la semejanza respecto de la comprensión en este artículo al utilizar en el mismo sentido sistema capitalista, economía de mercados y neoliberalismo económico.

La estructura del artículo tiene cuatro partes. Será muy difícil trazar una línea divisoria en su desarrollo, por lo que será una distinción de carácter formal. La primera presenta la relación entre economía, familia y ética en la que se hará un breve paso por sus relaciones etimológicas y por la historia, y se destacará el papel de la mujer en esa tríada conceptual. El segundo es el análisis crítico y muy general de esa realidad a partir de la Doctrina Social de la Iglesia considerando en particular algunas encíclicas sociales hasta la Centesimus annus. El tercero es la visión del capitalismo desde esta carta encíclica y, por supuesto, el Documento de Medellín, aunque es indudable que se tiene que entrecruzar en forma constante a lo largo de este. Finalmente, a manera de conclusión, se hace una propuesta de correlación para la teología y la pastoral familiar en la que se hará énfasis en la necesidad de plantear una teología moral para la familia renovada, lo que es volver al fundamento de la moral cristiana como es la revelación de Dios familia-Trinidad. 


\section{La relación de la economía con los valores de la familia: un poco de historia}

Es muy profunda la relación entre economía, familia y ética. Las mismas definiciones etimológicas así lo refieren. Economía refiere esta relación oikos-nomos (casa-normas), ethos (costumbre/conducta) y familia como famulus de famel (servidores que calman el hambre en una misma casa). Tal conexión interna se hace más evidente cuando es la madre quien tiene la función de distribución de los bienes para el bien de todos y en proporcionalidad con la necesidad de cada uno de sus miembros, mientras que el varón se encargaba de obtener esos bienes. Obviamente, esta concepción es fruto de evoluciones que están relacionados con el establecimiento de la familia, independiente de las religiones. Ahora bien, lo que hacen los libros sagrados o los mitos es reforzar estas formas con estos imaginarios y hermenéuticas que sustenten el modelo.

Así, por ejemplo, la creación del hombre y la mujer en la Biblia está inscrita en una línea de igualdad, pues son diferentes y complementarios, como indica la fórmula de la tradición sacerdotal: “y creó Dios al hombre a su imagen; a imagen de Dios lo creó; varón y hembra los creó" (Gn 1, 27). El ser humano es, desde el mismo origen, dual: no es primero el uno y luego el otro, como tampoco por encima del uno, sino ambos están vinculados a partir de su propia interdependencia. La misma hermenéutica puede hacerse de la tradición yahvista. Sin embargo, ha prevalecido una interpretación de "subordinación femenina" que también está en la Biblia en Ex 20, 17 o Dt 5, 21, en la que la mujer vale como propiedad de su marido, pero lo que más llama la atención es que sea desde esta hermenéutica de subordinación que se lea el texto de la creación yahvista, en la que Eva surge del costado de Adán y que esta relación es de propiedad (Pikaza, 1996).

El anterior ejemplo de la hermenéutica bíblica muestra la fuerza que tiene un paradigma dentro de la historia. Pueden cambiar los actores, los tiempos y los espacios, pero permanece por mucho tiempo el mismo modelo de interpretación y eso es lo que precisamente se deja ver cuando se habla de la familia o el matrimonio en el contexto eclesial (Celam, 1968). Pues, aunque se reconoce su situación de crisis, se mantiene la misma concepción basada en la ley natural, lo que representa un problema en la búsqueda de diálogo con otras ciencias que reconocen la familia como una construcción social y, por tanto, está determinada por los cambios en la sociedad, entre ellos, la economía y las formas de producción. No se debe entender la afirmación como si para la Iglesia el ámbito de lo social y económico no influyera en la familia, pero la gran diferencia es que, mientras las ciencias analizan 
el fenómeno y buscan entender sus dinámicas y referencias comprendiendo diferentes formas válidas de familia (Burguière, 1988), la Iglesia busca volver sobre la misma forma de familia y actuar pastoralmente en esa línea justificando su acción como verdad revelada, identificando también familia con matrimonio o pareja, lo cual significa que la crisis de una lleva a riesgo a la otra.

En referencia a la economía, actualmente se reconocen sus diversidades y evoluciones históricas, pero pareciera que, cuando se habla de la economía liberal y sus lógicas en el mercado, estas son concebidas como naturales y no construidas, lo que hace impensable e insensato cualquier cambio. Entonces, ¿en qué consiste la actividad económica y por qué surgió? La economía pretende proporcionar los medios adecuados para satisfacer las necesidades humanas según los recursos limitados que ofrece la naturaleza, que al ser desproporcionada esta relación entre la necesidad de satisfacción y los recursos hace necesaria esta actividad para buscar ese equilibro. Su naturaleza es social en tanto está en relación con otros, pero tiene también un carácter individual en la medida en que supone conciencia y libertad del ser humano.

La actividad económica, dado que se ha complejizado, se ha diversificado en sus funciones y dividido entre sus mismas áreas. Esta división no es solo en relación con aspectos de sí misma, como la producción, el comercio, el consumo, la moneda, entre otras, sino con respecto a las otras disciplinas desde igualdad de lenguajes. Su importancia en la actualidad es de tal magnitud que no existe una actividad humana que no esté en relación con ella, del mismo modo como lo fuera la teología en la Edad Media. Señala el Concilio Vaticano II que una dinámica así aumenta con el creciente dominio del ser humano sobre la naturaleza, específicamente por la tendencia de la extracción de la riqueza, la tecnificación del agro, la mayor interdependencia entre ciudadanos, asociaciones y países, la intervención del poder político, el aumento de los bienes y servicios, y el crecimiento de la empresa y de los capitales privados (Pablo VI, 1965).

El principio universal de la economía es el bien común de los recursos respecto de la satisfacción de la necesidad humana, personal y comunitaria. Históricamente se destacan dos modelos económicos contradictorios entre sí: el capitalista y el socialista. Cada uno de ellos se refiere a una forma específica de generar desarrollo y producción para distribuir la riqueza entre los ciudadanos, por eso están acompañados de una estructura en la organización del Estado, un marco jurídico y unas instituciones que facilitan una serie de procedimientos para llevar a cabo esa producción y distribución. Es ahí donde la familia, desde la concepción nuclear o extendida como la conocemos en nuestros países, se desarrolla o se expropia y se juega su futuro. 
Esta situación no es nada fácil cuando todos los lenguajes y las prácticas desdibujan esa realidad de la familia. Es decir, la familia y sus valores se la tienen que jugar en un contexto que podemos llamar, trayendo el lenguaje empresarial, "ley de la jungla", para lo que no hay límites que respetar, sino los deseos insaciables de mayor beneficio en que se resalta el valor de la familia si está ordenado al éxito. Una descripción interesante del perfil de estas personas ganadoras y llenas de éxito se encuentra en la novela de Tom Wolfe, La hoguera de las vanidades, pues se trata de logros individuales, sin referencias de valores propios de la familia. Ellos aparecen como "señores del universo", quienes son presentados por los medios de consumo cultural como los ídolos y se muestra su gesta mediante su ímpetu ostentoso como un ideal. Así se va tornando una forma de vida a imitar sin cuestionamientos, que hace propia el verso de Virgilio en la Eneida "audaces fortuna juvat" (la fortuna favorece a los audaces), lo que les implica aislarse de los valores de familia que le demoran o embolatan sus empeños individuales.

Ahora bien, este tipo de análisis tiene mucha fuerza porque responde a una concepción de la realidad mecanicista que nos viene con la revolución científica y su interés por tener un control sobre el mundo para dominarlo. La forma como se puede ejercer este dominio es fragmentar esa realidad y, desde ahí, actuar en consecuencia, es decir, sin unidad, sin integralidad. Paradigma este que explica por qué la vida familiar es leída como vida privada separada del ámbito de lo público. Por el contrario, la Iglesia desde los documentos eclesiales latinoamericanos aboga por una mirada integral y propone la imposibilidad de separar lo cotidiano de lo estructural, lo que significa que cuando hace un análisis de la sociedad está buscando leer en forma conjunta esa realidad y atenderla en el mismo sentido, aunque haya también hecho parte de este tipo de análisis racionalizado y sin rostro. Respetando y defendiendo la autonomía de las ciencias, en este caso de la economía, la Iglesia mantiene un diálogo abierto desde el lugar en que puede hablar como es el de la dignidad humana y en especial desde el lugar de quienes padecen las consecuencias de un modelo económico como los pobres en orden a la necesidad y como unidad de relaciones; la más afectada es indudablemente la familia (Celam, 1968).

La Iglesia no propone modelos económicos, ya que ellos solo pueden surgir del esfuerzo y el interés de todos los responsables en cada uno de los aspectos sociales, económicos, políticos y culturales, los cuales se entrecruzan entre sí. La Iglesia, desde la racionalidad teológica, expresa su contribución mediante un marco de referencias éticas basadas en el respeto por la vida, la dignidad humana y la justicia, con lo cual brinda orientación ideal mediante su doctrina social, la cual reconoce el sentido positivo del mercado y de la empresa cuando 
está orientada hacia el bien común y ahí la importancia de la familia como parte activa en esa orientación:

La familia es la primera escuela de virtudes sociales que necesitan todas las demás sociedades. Encuentran en la familia los hijos la primera experiencia de una sana sociedad humana [...] y se introducen poco a poco en la sociedad civil y en la Iglesia [...] Así la familia cumplirá su misión si "promueve la justicia y demás obras buenas al servicio de todos los hermanos que padecen necesidad". De ahí que "el bienestar de la persona y de la sociedad humana esté ligado estrechamente a una favorable situación de la comunidad conyugal y familiar", pues es esta un factor importantísimo en el desarrollo. (Celam, 1968, n. 7)

La Iglesia también valora la legitimidad del ejercicio del trabajo como forma de expresión de libertad y dignidad (Juan Pablo II, 1981), valora la asociación libre, la libre iniciativa y la propiedad privada. Reconoce el sentido de solidaridad presente en el modo de producción cuando se emplea para un trabajo útil y dignificante, lo que hace del trabajo un derecho de todas las personas para poder alcanzar mediante sus esfuerzos los modos de vida dignos y la realización de su proyecto de vida (Juan Pablo II, 1991). Todo este modelo, además del marco referencial, tiene un contenido axiológico y de orientaciones para la concreción en el mundo de la economía.

El marco de referencias de la teología en relación con la economía está constituido principalmente por el principio capital: "El hombre es el autor, el centro y el fin de toda actividad económica" (Juan XXIII, 1961, n. 219; Pablo VI, 1965, n. 63; Pablo VI, 1967, n. 34; Pío XI, 1931, n. 17). Sigue el carácter dialéctico de la economía que desde la perspectiva cristiana significa el establecimiento de la "creación" y la "redención" como referencia de los bienes económicos. Luego, la comprensión de la unidad de la historia y por tanto la igualdad de derechos para todos los seres humanos, pues todo está al servicio del hombre sin distinción de ninguna clase (Pablo VI, 1965). Finalmente, el criterio moral de la opción por el pobre es un rasgo normativo en la moral del cristiano.

En cuanto a los criterios valorativos, está el "destino común de los bienes económicos" (Pablo VI, 1965, n. 69), la satisfacción de la necesidad humana como fin supremo de la economía, lo que significa búsqueda de justicia y el rechazo de cualquier forma de escándalo mediante el lujo y el consumismo. Otro criterio 
importante es la actitud y responsabilidad por desenmascarar los modelos de productividad basados en lucro ilimitado y por el contrario propone un crecimiento sostenible y equilibrado del desarrollo. En fin, una actitud ética que beneficie a todos en el mundo, pero sobre todo a esa forma natural de relación y formación como es la familia. Precisamente, cuando la Doctrina Social de la Iglesia condena los sistemas económicos por sus excesos y por su falta de integralidad, lo está haciendo desde esa clave de lectura, pues su crítica se realiza en tanto se deshumaniza al ser humano en su dignidad y se desprecia a la familia.

Una cantidad importante de citas demuestra que este lenguaje ha sido recurrente desde León XIII en la encíclica Rerum novarum hasta el papa Francisco. Sin embargo, en algunas encíclicas, la crítica al sistema socialista abarca también al capitalismo (Juan Pablo II, 1987) y se plantea el mismo cuestionamiento para los dos sistemas: “¿De qué manera o en qué medida estos dos sistemas son susceptibles de transformaciones y capaces de ponerse al día, de modo que favorezcan o promuevan un desarrollo verdadero e integral del hombre y de los pueblos en la sociedad actual?" (n. 21).

Una de las críticas paradigmáticas del sistema socialista es la planteada por Juan Pablo II en la encíclica Laborem exercens:

Hay que tener presente que la simple sustracción de esos medios de producción (el capital) de las manos de sus propietarios privados, no es suficiente para socializarlos de modo satisfactorio. Los medios de producción dejan de ser propiedad de un determinado grupo social, o sea, propietarios privados, para pasar a ser propiedad de la sociedad organizada, quedando sometidos a la administración y al control directo de otro grupo de personas, es decir, de aquellas que, aunque no tengan su propiedad por más que ejerzan el poder dentro de la sociedad, disponen de ellos a escala de la economía nacional entera, o bien de la economía local. (1981, n. 14)

Por la variabilidad histórica, es conveniente plantear una diferencia en la valoración de la Doctrina Social de la Iglesia de cada uno de los sistemas, para ello es preciso tomar como referencia específica el capitalismo y desde allí hacer la respectiva inferencia al socialismo como modelo. El punto de quiebre de esta valoración está en la crisis y caída del socialismo que coincide con la publicación de la Centesimus annus; luego habrá un cambio en el discurso. 


\section{Perspectiva crítica de la Doctrina Social de la Iglesia hasta la Centesimus annus}

Esta delimitación no es una decisión caprichosa por parte del investigador, sino que obedece a un cambio histórico en el mundo, como es la sonada debacle del socialismo de la Europa oriental y la correspondiente apertura a los mercados de economía dominantes en la otra parte de Europa y, principalmente, de los Estados Unidos. Este cambio histórico supone un cambio de discurso, pues una cosa es señalar críticas al capitalismo teniendo la mirada puesta en el socialismo y otra es penetrar su crítica en el capitalismo en sí mismo.

En este sentido, la valoración del capitalismo a partir de los logros en materia tecnológica es justificada por el progreso industrial y sus aportes al desarrollo, sin desconocer que ha sido un sistema causante de muchos sufrimientos y luchas fratricidas (Pablo VI, 1967). La Rerum novarum se inclina por describir la perversidad del modelo de contratación obrera y la escandalosa acumulación de capital y bienes en manos de pocos que abusan de las necesidades de las mayorías pobres mediante los reducidos salarios, quienes no tienen más opción que someterse a la "crueldad de los ambiciosos que abusan de las personas sin moderación, como si fueran cosas para su medro personal" (León XIII, 1891, n. 2).

Pío XI (1931) asegura que después de un análisis de carácter histórico-paradigmático que describe logros y desaciertos del capitalismo se ha encontrado que la acumulación de capital está "plagada de vicios gravísimos" (n. 28). Dada su claridad es válido recogerlos en unas cuantas líneas:

Esta acumulación de poder y de recursos, nota casi característica de la economía contemporánea, es el fruto natural de la ilimitada libertad de los competidores, de la que han sobrevivido solo los más poderosos, lo que con frecuencia es tanto como decir los más violentos y los más desprovistos de conciencia. Tal acumulación de riquezas y de poder origina, a su vez, tres tipos de lucha: se lucha en primer lugar por la hegemonía económica; se entabla luego el rudo combate para adueñarse del poder público para así abusar de su influencia y autoridad en los conflictos económicos; finalmente, pugnan entre sí los diferentes Estados, ya porque las naciones emplean su fuerza y su política para promover cada cual los intereses económicos de sus súbditos, ya porque tratan de dirimir las controversias políticas surgidas entre las naciones, recurriendo a su poderío y recursos económicos [...] la dictadura económica se ha adueñado del mercado libre; por consiguiente, al deseo 
de lucro ha sucedido la desenfrenada ambición de poderío; la economía toda se ha hecho horrendamente cruel, atroz. A esto se añaden los datos gravísimos que han surgido de la deplorable mezcla y confusión entre las atribuciones y cargas del Estado y las de la economía, entre los daños se indica como uno de los más graves, una cierta caída del prestigio del Estado que, libre de todo interés de partes y atento exclusivamente al bien común y a la justicia, debería ocupar el elevado puesto de rector y supremo árbitro de las cosas; se hace por el contrario, esclavo, entregado y vendido a la pasión y a las ambiciones humanas. (Pío XI, 1931, n. 105)

Interesante el análisis, pero en el mismo sentido se plantea la necesidad de correctivos dentro del sistema y no se juzga desde su significación estructural, que es donde se encuentra la moralidad o inmoralidad. Es decir, los vicios son entendidos como imperfecciones en un desarrollo histórico del sistema, como parte de su evolución, pero no en cuanto al sistema en sí mismo, lo que significa un aporte valiente y significativo, pero al mismo tiempo corto en sus alcances, por cuanto se trata de un análisis profundo de su estructura, no por la funcionalidad jurídica, sino por la funcionalidad real. Además, que los cambios en un sistema se pueden lograr desde la voluntad de las personas que en su discernimiento lo vean así posible, es necesario considerarlo con detenimiento. Eso se confirma cuando se valora formal y legalmente el sistema capitalista como un sistema que no es condenable en sí mismo y que no es por naturaleza vicioso como tal:

Y realmente no es viciosa por naturaleza, sino que viola el recto orden solo cuando el capital abusa de los obreros y de la clase proletaria con la finalidad y de tal forma que los negocios e incluso toda la economía se plieguen a su exclusiva voluntad y provecho, sin tener en cuenta para nada ni la dignidad humana de los trabajadores, ni el carácter social de la economía, ni aun siquiera la misma justicia social y bien común. (Pío XI, 1931, n. 101)

Es de subrayar que dentro de los análisis de la Doctrina Social de la Iglesia al capitalismo la valoración económico-estructural es la más profunda, no solo por el lenguaje utilizado por el papa Pablo VI (1967), sino por la agudeza retomada en el discurso a la Unión Cristiana de Emprendedores y Dirigentes en 1964, el cual fue tomado como referencia en el Concilio en la nota 7 de Gaudium et spes. Allí, el papa Pablo VI plantea una serie de interrogantes a los empresarios que apuntan a la estructura básica del capitalismo: 
¿Quién se atrevería a sostener que el fenómeno sociológico derivado de la organización moderna del trabajo es un fenómeno de perfección, de equilibrio y tranquilidad? ¿No es verdad precisamente lo contrario? ¿No lo prueba nuestra historia de forma evidente? [...] La empresa, que por exigencia constitucional pide colaboración, un acuerdo, una armonía, ¿no es, acaso, hoy todavía una fricción de espíritus y de intereses? [...] Ha de tener algún vicio profundo, una radical insuficiencia este sistema, si desde sus comienzos cuenta con semejantes reacciones sociales [...] Es verdad que quien hoy hable, como hacen muchos, del capitalismo con los conceptos que lo definieron el siglo pasado, da una prueba de estar retrasado con relación a la realidad de las cosas; pero es un hecho que el sistema económico social, creado por el liberalismo manchesteriano y que todavía perdura en el criterio de la unilateralidad de la posesión de los medios de producción, de la economía encaminada a un provecho privado prevalente, no trae la perfección, no trae la paz, no trae la justicia, si continúa dividiendo a los hombres en clases irreductiblemente enemigas, y caracteriza a la sociedad por el malestar profundo y lacerante que la atormenta, apenas contenido por la legalidad y la tregua momentánea de algunos acuerdos en la lucha sistemática e implacable, que debería llevarla a la opresión de una clase contra la otra. (1964, n. 26)

Lo expuesto hasta aquí deja varias preguntas que pueden leerse de diversas maneras, una de ellas que no siempre la Iglesia ha visto una relación entre el individualismo del capitalismo, las injusticias de un modelo económico basado en la exclusión y el futuro de la familia. También puede conferirse que esta falta de conexión interna entre el capitalismo y la familia está precisamente porque en cierto modo heredó esa fragmentación de la modernidad. También puede explicarse por la falta de humildad en el discurso y su desprecio por la secularización, además de la pérdida de unidad interna dentro de la misma teología que se distancia de la Biblia y la Tradición y se refugia más en lo normativo.

\section{El capitalismo desde la Centesimus annus}

Una de las características de esta encíclica es su estructura hermenéutica circular en la que se entrecruzan los criterios y las lecturas. Por ejemplo, la crítica del capitalismo contrasta con la justificación de la estructura de mercado y la aceptación 
de la legitimidad estructural y en su "reformabilidad". En concreto, hace una valoración y crítica de cada sistema por separado. El socialismo correspondiente a su forma histórica de la Unión de Repúblicas Socialistas Soviéticas (URSS) es condenado de manera abierta y clara, sistema que es asociado al marxismo, la cosmovisión atea y la configuración de un Estado totalitario que viola los derechos humanos. La argumentación realizada para hacer esta condena se plantea desde tres niveles: el primero es el antropológico en tanto reduce al hombre a un ser de relaciones sociales y desaparece el concepto de persona como sujeto autónomo de decisión moral; segundo, la estrategia de promover la lucha de clases como una forma de supuesta lucha por el bien común; y tercero, por la ineficacia de su sistema económico, el cual está sostenido sobre la base de un no reconocimiento de los derechos sobre la iniciativa, la propiedad y la libertad (Juan Pablo II, 1991).

Así, certifica la derrota del socialismo, el cual no puede confrontar al capitalismo como modelo, sin embargo, esto no significa que el capitalismo sea victorioso: "queda mostrado cuán inaceptable es la afirmación de que la derrota del socialismo deje al capitalismo como único modelo de organización económica" (Juan Pablo II, 1991, n. 35). El razonamiento del papa es muy interesante, pues el fracaso de una no es el triunfo de la otra, por eso persisten los problemas de desempleo, marginación, dependencia y desigualdades en las relaciones económicas laborales y empresariales, pero a los cuales se busca reconstruir mediante la humanización y la concreción en fórmulas históricas eficaces.

La propuesta de la encíclica es, en primer lugar, aceptar la validez del capitalismo como estructura económica fundamental (libre), entendido como un sistema económico que reconoce el papel de la empresa, el mercado, la propiedad, entre otras. Su desarrollo es realizado desde la realidad de la propiedad privada, la empresa, el mercado y los beneficios y el interés individual, y cada una de ellas tiene una orientación ética que la justifica y relaciona con el universo de la ética (Juan Pablo II, 1991). Esta matización que hace la Doctrina Social de la Iglesia sobre la estructura económica libre y el sistema capitalista deja una pregunta: ¿existe un sistema económico ideal que garantice las condiciones éticas de la economía libre que al mismo tiempo promocione los valores de la familia?

La respuesta que la Iglesia plantea, como se ha dicho, es no proponer modelos económicos, pues esta es una respuesta técnica que depende del contexto sociohistórico y del esfuerzo de todos los responsables de brindar esta respuesta (Juan Pablo II, 1991). Lo que ofrece la Iglesia es una iluminación a partir de unos principios orientadores para que los modelos económicos respondan integralmente al desarrollo humano y de las sociedades y, por ende, de las familias. Estos principios son: 
- $\quad$ Reconocimiento de la importancia del mercado y de la empresa encaminada al bien común.

- Legitimidad de los esfuerzos de los trabajadores por lograr espacio de participación empresarial y respeto de sus derechos, así como el ejercicio de su libertad y desarrollo.

- La empresa es una organización de personas, no solo de capitales, que aportan su trabajo desde funciones diversas para lograr el objetivo que se proponen respecto de bienes, servicios, entre otros, siempre promoviendo el desarrollo y la liberación integral de las personas.

- La propiedad de los medios de producción en cualquier sector es legítima cuando está ordenada al trabajo útil y a la promoción humana.

- $\quad$ El trabajo es un derecho y una forma de contribuir a la justicia y paz social.

En este sentido, la encíclica reconoce como legítimo la lucha contra un sistema económico injusto y las formas de lucha de los sindicatos buscando un modelo de sociedad desde el trabajo libre, la empresa y la interacción participativa: "Esta sociedad tampoco se opone al mercado, sino que exige que este sea controlado oportunamente por las fuerzas sociales y por el Estado, de manera que se garantice la satisfacción de las exigencias fundamentales de toda la sociedad" (Juan Pablo II, 1991, n. 35).

La actitud del cristiano no puede ser pasiva y dejarse envolver y deslumbrar por el progreso material que se asimila con desarrollo, ni tampoco puede tomar una postura de crítica mordaz sin discernimiento activo y responsable. La respuesta es el mismo Jesucristo que ofrece a todos unos caminos de paz, justicia y libertad verdadera. La Iglesia está llamada a proponer una justicia nueva, la justicia del Reino de Dios para transformar la sociedad, pero esta es posible siguiendo la insistencia tradicional de la Doctrina Social de la Iglesia, con la conversión del corazón de las personas con las cuales se hace posible la transformación de las estructuras sociales.

Hay una evidencia difícil de delimitar cuando se hace el análisis sobre el neoliberalismo y es la asociación del término con las políticas económicas que siguen los gobiernos inspiradas en el pensamiento de Ludwig von Mises, Friedrich Hayek y Milton Friedman, quienes proponen la desregulación de cualquier forma de mercado respetando un orden espontáneo, la "catalaxia", lo que lleva a una serie de progresos materiales, científicos y de diferente índole que se traducen en crecimiento económico pero concentrado en pocas manos, lo que aumenta la desigualdad y la inequidad social. La otra es la relación del término con economía de mercado que se absolutiza como la única forma de relación económica, 
que en forma darwinista significa que no puede bastarse a sí misma y develar una contradicción inherente al mismo mercado como es la competencia.

El análisis de la Centesimus annus es parte de un proyecto único con la Veritatis splendor. Un ejemplo de este lenguaje de continuidad de un proyecto está en los interrogantes sobre el milenio que se da en clave de invitación en la Centesimus annus:

Invito a mirar el futuro, cuando ya se vislumbra el tercer milenio de la era cristiana, cargado de incógnitas, pero también de promesas. Incógnitas y promesas que interpelan nuestra imaginación y creatividad, a la vez que estimulan nuestra responsabilidad, como discípulos del único maestro, Cristo (Cf. Mt 23, 8), con miras a indicar el camino, a proclamar la verdad y a comunicar la vida que es él mismo (Cf. Jn 14, 6). (n. 3)

Es en la Veritatis splendor donde se ofrece el camino: "La Iglesia, pueblo de Dios en medio de las naciones, mientras mira atentamente a los nuevos desafíos de la historia y a los esfuerzos que los hombres realzan en la búsqueda del sentido de la vida, ofrece a todos la respuesta que brota de la verdad de Jesucristo y de su Evangelio" (Juan Pablo II, 1993, n. 2). Así, puede verse como un proyecto común en el que lo que se plantea en la primera encíclica es desarrollado por la segunda. En referencia a los sistemas ideológicos, por ejemplo, se denuncia el sentido de una democracia que por sí misma no es buena, sino que puede ser totalitaria. Reconoce que es auténtica si asegura la participación de los ciudadanos en las opciones políticas y ejerce control sobre la gestión de sus gobernantes. Entre otras cosas, también reconoce que es posible dentro de un Estado legítimo:

Una auténtica democracia es posible solamente en un Estado de derecho y sobre la base de una recta concepción de la persona humana. Requiere que se den las condiciones necesarias para la promoción de las personas concretas, mediante la educación y la formación en los verdaderos ideales, así como de la "subjetividad" de la sociedad mediante la creación de estructuras de participación y de corresponsabilidad. Hoy se tiende a afirmar que el agnosticismo y el relativismo escéptico son la filosofía y la actitud fundamental correspondientes a las formas políticas democráticas, y que cuantos están convencidos de conocer la verdad y se adhieren a ella con firmeza no son fiables desde el punto de vista democrático, al no aceptar que la verdad sea determinada por la mayoría o que sea variable según los diversos equilibrios políticos. A este propósito, hay que observar que, si no existe una verdad última, la cual guía y orienta la acción política, entonces las ideas y las 
convicciones humanas pueden ser instrumentalizadas fácilmente para fines de poder. Una democracia sin valores se convierte con facilidad en un totalitarismo visible o encubierto, como demuestra la historia.

La Iglesia tampoco cierra los ojos ante el peligro del fanatismo o fundamentalismo de quienes, en nombre de una ideología con pretensiones de científica o religiosa, creen que pueden imponer a los demás hombres su concepción de la verdad y del bien. No es de esta índole la verdad cristiana. Al no ser ideológica, la fe cristiana no pretende encuadrar en un rígido esquema la cambiante realidad sociopolítica y reconoce que la vida del hombre se desarrolla en la historia en condiciones diversas y no perfectas. La Iglesia, por tanto, al ratificar constantemente la trascendente dignidad de la persona, utiliza como método propio el respeto de la libertad.

La libertad, no obstante, es valorizada en pleno solamente por la aceptación de la verdad. En un mundo sin verdad la libertad pierde su consistencia y el hombre queda expuesto a la violencia de las pasiones y a condicionamientos patentes o encubiertos. El cristiano vive la libertad y la sirve (Cf. Jn 8, 31-32), proponiendo continuamente, en conformidad con la naturaleza misionera de su vocación, la verdad que ha conocido. En el diálogo con los demás hombres y estando atento a la parte de verdad que encuentra en la experiencia de vida y en la cultura de las personas y de las naciones, el cristiano no renuncia a afirmar todo lo que le han dado a conocer su fe y el correcto ejercicio de su razón. (Juan Pablo II, 1991, n. 46)

Metodológicamente, es importante considerar una regla hermenéutica: leer el documento teniendo en cuenta el contexto eclesial desde el cual y para el cual se escribe; entendido, además, específicamente desde su dinámica interna, teniendo como referente un conjunto histórico más amplio, en el que la situación actual se inserta.

La eclesiología en el contexto del Concilio Vaticano II es de creatividad, pero años después de ese entusiasmo se insiste en la seguridad doctrinal, pues ese paradigma de la escuela romana retoma su liderazgo en la encíclica Veritatis splendor, y de un tono abierto y de diálogo se pasa a un estilo doctrinal que no ha generado aceptación por parte de los teólogos moralistas en especial en lo referente a la moral vida-persona (Vidal, 2000, p. 547). En cuanto a la valoración 
ideológica, llama la atención la teología de la libertad de la encíclica Libertas praestantissimum de León XIII (1888) que es la expresión de la doctrina presente en la Iglesia mediante sus documentos oficiales y es la de una visión integrista fundamentada en la filosofía platónica en la que la historia real y concreta queda eludida por "principios eternos" $\mathrm{y}$, como consecuencia, pasa por alto todos los actos de injusticia, de terror liderados o avalados por la Iglesia.

Es preciso recordar que el contexto de las encíclicas sociales es la conquista de los derechos civiles y políticos de los individuos frente al Estado que se hicieron presentes en las constituciones liberales de los diferentes países a lo largo de la geografía mundial, pero en las que persiste una forma de dominación como los derechos de propiedad y de libertad de las empresas y el mercado que imponen una lógica de competencia y de acumulación de capital, que en la práctica se traduciría en injusticias sociales y laborales, y darían lugar al surgimiento de los movimientos obreros para conquistar la segunda generación de derechos como los económicos y sociales. Es una ocasión nuevamente de confrontación de la Iglesia que, en un primer momento, condena radicalmente esas pretensiones de conquista del movimiento obrero, pero al mismo tiempo propone una alternativa como es la formulación de la Doctrina Social de la Iglesia centrada en la resolución de los conflictos en la concertación, aunque no de transformaciones estructurales, es decir, los abusos del capitalismo.

Recordemos que había un contexto de rechazo del capitalismo con algunos movimientos sociales, pues se experimentaba un conflicto en los siglos XIX y XX por el desmedido derecho de propiedad privada desde la empresa. Están los socialistas utópicos (1820-1870) con propuestas socialistas. Luego se da el Manifiesto Comunista (1848), que propone un modelo internacionalista y revolucionario que va a la conquista de los derechos laborales de los obreros. Finalmente están las experiencias concretas de los Estados comunistas y socialistas con la Revolución rusa de 1917 y su desarrollo posterior. Ante este panorama de alternativas la clase obrera se adhirió al modelo socialista como respuesta ideológica que fundamentaba su lucha, pero las formas de adopción de esa lucha no estaban en el mismo nivel. Se destacan las organizaciones cooperativistas, las que buscan prescindir del Estado como los anarquistas y las que buscan la transformación estructural como es el caso de los marxistas:

Pío IX, bajo el título de socialismo y comunismo, condena en realidad a los socialistas utópicos; León XIII, bajo el mismo título, condena el anarquismo. Pío XI es el primero que menciona a Marx por su nombre, pero en realidad se refiere a una forma particular de marxismo: la interpretación bolchevique del mismo. (Gaete, 1972, p. 330) 
La postura de la Iglesia, como se ha dicho, es de condena al comunismo, pero esta se realiza identificando hechos que son incompatibles con la Iglesia sin análisis teórico fundamentado para realizarlo. El planteamiento y lenguaje responden a un criterio práctico, por eso el uso de un lenguaje generalizado cuando, por ejemplo, habla Pío IX de los movimientos en Europa como convulsiones liberales, sin determinar a qué específicamente se refiere, es común en el discurso de la Iglesia, pues lo que le interesa remarcar es la alternativa de la Doctrina Social de la Iglesia con unos ejes centrales, los cuales se pueden resumir en:

Defensa radical del derecho a la propiedad privada, transmisible por la estructura familiar; la negación del igualitarismo como contrario a la ley natural; el reconocimiento, por igual, de los derechos del capital y del trabajo en el funcionamiento de la economía; la armonía de clases como alternativa al antagonismo de clases, regida por criterios de justicia y caridad; la defensa de la autoridad del Estado y la atribución a este de un moderado papel promotor de la armonía de clases; la valoración espiritual de la pobreza, de la paciencia y de la resignación; la promoción de las asociaciones de obreros y patronos, como base de una concertación permanente. (Giraldo, 2008, p. 44)

El modelo seguido por la Iglesia mediante las encíclicas es, evidentemente, condenar los efectos sociales trágicos del capitalismo, pero su modo es exhortativo y, en cierto modo, ingenuo, al considerar que desde la conversión individual y voluntaria es que se pueden transformar esos efectos al tiempo que estructuralmente mantiene como "derecho natural" la propiedad como clave de la concepción capitalista. Su papel como institución en ese contexto conflictivo que acompaña el comienzo y la mitad del siglo XX con guerras es de ser mediadora, pero es claro que sus pronunciamientos no son imparciales, sino que estratégicamente defenderán los intereses capitalistas, lo cual es aprovechado por las naciones capitalistas para sumarse con esta lectura legitimadora de la Iglesia a las condenas al comunismo, las cuales identificarán descaradamente capitalismo con civilización cristiana. Esta es la razón de por qué desestiman la propuesta de la mano tendida que ofrecen los partidos comunistas de los países católicos con la que proponen revisar las formas de integración con la Iglesia en beneficio de los más desfavorecidos por ser enemigos irreconciliables (Pío XI, 1937).

Luego de establecerse un juicio en la historia y reconocer la falta de profetismo, se esperaba un lenguaje más directo, pues no solo hay un silencio con un modelo económico que arrastra algo muy importante como es la familia y sus valores, sino que deja que esta se vea amenazada mientras el contenido doctrinal 
sobre la familia permanecía centrado en el matrimonio y esta se considerase como una extensión de este, de modo que no se relacionaba crisis del modelo económico con la crisis de la familia. Esa ambigüedad se hace evidente con el uso del lenguaje teológico abstracto sin referencia a la fe. Esto quiere decir que se presenta un lenguaje desconectado de la experiencia de vida de la gente y de sus angustias.

Lo anterior plantea un reto interesante para la Iglesia y la forma de presentación de su doctrina, pues no puede seguir apelando sin más a los formatos conceptuales, sino que ha de encontrar otros lenguajes para ser escuchada y hacer que las orientaciones que ofrece puedan ser realmente tenidas en cuenta por las comunidades, pues no solo es un tema de abstracción, sino que, cuando se trata de lo moral, suele estar presente esa moral de obligación por encima de la espiritualidad.

\section{A manera de conclusión: redireccionamiento de la teología moral para la familia}

En las últimas décadas, se ha generado una serie de intentos en la teología por renovarse y tomar en serio la tarea propuesta de la Optatam totius, y para ello ha vuelto sobre la experiencia original de la primitiva comunidad eclesial narrada en el Evangelio y expresada en la Tradición a través de elementos normativos, de modo que el misterio de la Trinidad como verdad fundante y diferenciadora de la fe cristiana no es ofrecida como doctrina que haya que profundizar, sino como comunión que hay que vivir en el Espíritu, siguiendo el camino del Hijo, para ir al encuentro del Padre. Por tanto, no es solo la presencia, sino que es también la promesa de Dios de salvación la que llena de sentido la existencia humana, y su obrar moral sea el contexto que corresponda y al que nos orienta el Documento de Medellín.

Este quehacer hermenéutico supone la tarea de defender el sentido razonable (Gadamer, 1967) de esta confesión trinitaria en la comunidad y especialmente en la familia que es donde acontece la presencia amorosa de Dios, y que por fuerza la fragmentación de la racionalidad moderna

pareciera ser una reliquia sagrada convertida en ritual, que, aunque no se la niegue en general, aunque se la viva en el marco del lenguaje homogéneo y del gesto litúrgico de la Iglesia, difícilmente llega, sin embargo, a plasmar el acto personal, existencial de fe y, menos aún, la comprensión de la propia existencia y del mundo. (Greshake, 2001, p. 31) 
Esta actualidad dinámica de la interpretación tiene también un propósito pedagógico, como el de mostrar el camino para que los hombres y las mujeres de hoy comprendan que es posible creer en la Trinidad de Dios y dejarse transformar por este amor de comunión e invadir de esperanza nuestra historia a través de nuestros actos responsables, y el espacio ideal para esta concreción es la familia.

Esta proyección anticipada de la gloria de Dios debe ser una condición actitudinal por parte del creyente que irradie su entorno familiar. Supone en el teólogo una predisposición afectiva amorosa para el estudio de la fe, de sentido del misterio y de compromiso con el pueblo (Boff, 1998). Se entiende el acto hermenéutico con sentido propositivo, no quedándose en el horizonte del texto, sino en la producción de horizontes existenciales y de compromiso con la justicia social: "Ir a Dios es ir al pobre" (Sobrino, 1977, p. 167) e "Ir a la Trinidad es ir a la familia", pues la familia es, como señala Kasper (1990), la gramática del amor de Dios y su fidelidad.

Esto indica también que el texto de la tradición, el contexto de situación y el propósito redentor y liberador son los elementos en juego en el acto de la interpretación en la teología moral que está presente en el documento que nos inspira (Celam, 1968). Son estos tres elementos en juego como procede una teología que pretende entrar en diálogo con el hombre, con el mundo, con los problemas que vive, y en ese diálogo ofrecer un camino válido para recuperar el sentido de la existencia personal y comunitaria. Se establece, por tanto, que la aplicación es un momento fundamental del proceso hermenéutico tan esencial e integral como lo es la comprensión y la interpretación (Gadamer, 1967). Por eso, no se pueden quedar por fuera esas líneas de orientación para una pastoral familiar que tiene su fundamentación en una teología moral renovada que no se apoya en un arbitrario subjetivismo, ni en una simple deducción de un principio moral prefijado para determinar la conducta del hombre y menos si hablamos de familia (Celam, 1968).

La propuesta de Medellín sobre la pastoral familiar está comprendida en el mismo contexto de renovación en que se encuentran todas las disciplinas teológicas. Esta opción implica una tarea esencial como es llevar la interpretación al lugar de la moral y que, según Hortelano (1991), debe configurarse al mismo tiempo como carisma, ciencia, kerigma, praxis, lenguaje y magisterio, si pretende alcanzar su objetivo de estudiar el misterio cristiano como imperativo. Articulación esta que debe hacerse en profundidad, como en una especie de metamoral en la pastoral:

Allí donde se juegan las grandes opciones fundamentales del hombre

y que no es otra cosa que el dinamismo radical del cosmos tal como ha 
sido proyectado por Dios y que ofrece unas posibilidades ilimitadas de futuro. Es una especie de gigantesco surtidor metafísico y trascendental [...] La misma irrupción histórica de Dios con su palabra, personalmente y con su Espíritu, se sitúa en esa metamoral profunda y radical. (Hortelano, 1991, p. 191)

Se abre entonces una propuesta de renovar en forma permanente la teología moral y la pastoral a partir de nuevas comprensiones que generan una mejor respuesta como la perspectiva ecosistémica, pues supone una mirada y una atención integral por el carácter multifactorial que la define actualmente y en la que esa realidad del sistema económico necesariamente influye de manera importante, y la respuesta en este caso no sería simplemente tener discursos contrarios, sino prácticas y espiritualidades que apelen a poner la familia, sea cual sea su concreción histórica, como la mejor forma de humanizar la economía.

\section{Referencias}

Beck, U. (1998). ¿Qué es la globalización? Falacias del globalismo, respuestas a la globalización. Barcelona, España: Paidós.

Boff, C. (1998). Teoria do metodo teológico. Petrópolis, Brasil: Vozes.

Boff, L. (2004). Ética y moral: la búsqueda de los fundamentos. Santander, España: Sal Terrae.

Burguière, A. (Coord.) (1988). Historia de la familia. Vol. 1: Mundos lejanos, mundos antiguos. Madrid, España: Alianza.

Burguière, A. (Coord.) (1988). Historia de la familia. Vol. 2: El impacto de la modernidad. Madrid, España: Alianza.

Concilio Vaticano II. (1970). Constituciones, decretos, declaraciones. Madrid, España: Biblioteca de Autores Cristianos.

Consejo Episcopal Latinoamericano. (1968). Documentos finales de Medellín. Medellín, Colombia: Autor.

Gadamer, H.-G. (1967). Verdad y método. Ciudad de México, México: Fondo de Cultura Económica.

Gaete, A. (1972). Los cristianos y el marxismo: de Pío XI a Paulo VI. Revista Mensaje, 21(209), 328-332.

Giraldo, J. (2008). Derechos humanos y cristianismo: trasfondos de un conflicto. Madrid, España: Dykinson.

Greshake, G. (2001). El Dios uno y trino. Barcelona, España: Herder. 
Hinkelammert, F. (1970). Ideologías del desarrollo y dialécticas de la historia. Buenos Aires, Argentina: Paidós.

Hortelano, A. (1991). Problemas actuales de Moral. Vol. I: Introducción a la teología moral. Salamanca, España: Sígueme.

Juan Pablo II. (1981). Laborem exercens. Recuperado de https://w2.vatican.va/content/ john-paul-ii/es/encyclicals/documents/hf_jp-ii_enc_14091981_laborem-exercens. html

Juan Pablo II. (1987). Sollicitudo rei sociales. Recuperado de http://w2.vatican.va/content/john-paul-ii/es/encyclicals/documents/hf_jp-ii_enc_30121987_sollicitudorei-socialis.html

Juan Pablo II. (1991). Centesimus annus. Recuperado de http://w2.vatican.va/content/ john-paul-ii/es/encyclicals/documents/hf_jp-ii_enc_01051991_centesimus-annus.html

Juan Pablo II. (1993). Veritatis splendor. Recuperado de http://w2.vatican.va/content/ john-paul-ii/es/encyclicals/documents/hf_jp-ii_enc_06081993_veritatis-splendor.html

Juan XIII. (1961). Mater et magistra. Recuperado de http://w2.vatican.va/content/johnxxiii/es/encyclicals/documents/hf_j-xxiii_enc_15051961_mater.html

Kasper, W. (1990). Teología el matrimonio cristiano. Santander, España: Sal Terrae.

León XIII. (1891). Rerum novarum. Recuperado de http://w2.vatican.va/content/leoxiii/es/encyclicals/documents/hf_l-xiii_enc_15051891_rerum-novarum.html

Pablo VI. (1965). Gaudium et spes. Recuperado de http://www.vatican.va/archive/ hist_councils/ii_vatican_council/documents/vat-ii_const_19651207_gaudium-etspes_sp.html

Pablo VI. (1967). Populorum progresssio. Recuperado de http://w2.vatican.va/content/ paul-vi/es/encyclicals/documents/hf_p-vi_enc_26031967_populorum.html

Pablo VI. (1971). Octogesima adveniens. Recuperado de http://w2.vatican.va/content/ paul-vi/es/apost_letters/documents/hf_p-vi_apl_19710514_octogesima-adveniens.html

Pikaza, X. (1996). Hombre y mujer en las religiones. Navarra, España: Verbo Divino.

Pío XI. (1931). Quadragesimo anno. Recuperado de http://w2.vatican.va/content/piusxi/es/encyclicals/documents/hf_p-xi_enc_19310515_quadragesimo-anno.html

Pío XI (1937). Divini redemptoris. Recuperado de http://w2.vatican.va/content/pius-xi/ es/encyclicals/documents/hf_p-xi_enc_19370319_divini-redemptoris.html

Romero Saint, O. A., Cardenal, R., Martín-Baró, I. y Sobrino, J. (1980). La voz de los sin voz: la palabra viva de monseñor Romero. San Salvador, El Salvador: Universidad Centroamericana José Simeón Cañas. 
Sobrino, J. (1977). Cristología desde América Latina: esbozo a partir del seguimiento del Jesús histórico. Ciudad de México, México: CRT.

Vidal, M. (2000). Nueva moral fundamental: el hogar teológico de la ética. Bilbao, España: Desclée de Brouwer. 